\title{
Editorial: Mapping the Structure of International Research Collaboration Network and Knowledge Domains on Electronic Commerce in the Journal of Theoretical and Applied Electronic Commerce Research
}

\author{
Guillermo Armando Ronda-Pupo ${ }^{1}$, Aurora Sánchez ${ }^{1}$ and Narciso Cerpa ${ }^{2}$ \\ ${ }^{1}$ Universidad Católica del Norte, Departamento de Administración, Chile. Universidad de Holguín, Cuba \\ gronda@ucn.cl \\ 'Universidad Católica del Norte, Departamento de Administración, Chile \\ asanchez@ucn.cl \\ ${ }^{2}$ Universidad de Talca, Facultad de Ingeniería, Curicó, Chile, \\ Editor-in-Chief \\ ncerpa@utalca.cl \\ September 2015
}

\section{Introduction}

E-commerce has been an academic research discipline and a domain of practice since the 1990s, when the use of internet for commercial purposes started. This novel field of research required new venues to disseminate and present research ideas that could capture e-commerce knowledge from academia and industry. The Journal of Theoretical and Applied Electronic Commerce Research (JTAER) came to provide a space for this purpose in 2006 and since that time it has been a channel where researchers could publish their work. In the meantime, research topics on e-commerce have been evolving to reflect technological advancements and changes in society. These changes have impacted the patterns of collaboration among researchers around the world and the structure of knowledge-core subjects, concepts and phenomena- on e-commerce.

This editorial explores the research published in the Journal of Theoretical and Applied Electronic Commerce Research (JTAER) from 2007 (i.e., since JTAER was indexed in Scopus) to 2014, providing a systematic review of the international collaboration patterns and the knowledge areas addressed by the journal. The objectives pursued by this study are:

1. Illustrate the structure of the international collaboration network on e-commerce using the Journal of Theoretical and Applied Electronic Commerce Research (JTAER)

2. Identify the major domains of knowledge published in this journal

3. Depict international collaboration in these major domains of knowledge

To achieve these objectives, 175 research documents, published in JTAER between 2007 and 2014, in the category articles are analyzed. International collaboration among researchers in this journal is mapped using social network analysis techniques to identify the countries that collaborate and the ones that serve as a bridge for communication with other countries. Knowledge areas in the articles published in JTAER are mapped in accordance to the most relevant framework that structured the domains and themes in e-commerce research today [20].

\section{International Collaboration and Electronic Commerce Research}

Research on international academic collaboration has witnessed a sustained increase interest from the worldwide scientific community in recent years [3], [7], [8], [12], [13], [14], [21], [22], [23], [24]. Research results suggest that the increase of international collaboration has fostered the citation impact of articles. For example, a research study reports that articles by authors from two different countries receive on average about $50 \%$ more citations than articles written by authors from a single country [6]. Another study reports that for science in general, articles published in international collaboration are cited twice as much as those published by means of the collaboration among authors coming from one country [10]. There is strong evidence that internationally co-authored publications have a higher impact than domestic ones [18]. A recent study found that Latin American papers on management published through international collaboration have 1.59 times more impact than those published through only domestic collaboration [15]. A different study researched the collaboration patterns and their relationships to the impact of the documents published in the field of management [24]. The authors analyze the collaboration networks of Chinese scholars and state that the accumulated number of Chinese authors and the accumulated number of articles published by Chinese authors increase by exponential form. Studies on the conformation and evolution of collaboration networks of a particular discipline through a journal are scarce. We are not aware of any previous study on the patterns of international collaboration research networks in e-commerce literature. 


\section{Knowledge Domains in Electronic Commerce Research}

The Internet was the main driving force behind the development of electronic commerce. From its beginning researchers have presented different frameworks to classify electronic commerce research and its development. One of the first frameworks [25] divides the topics of electronic commerce into: infrastructure; services; and products and structures. At the lower level, infrastructure consists of functions such as: wide-area telecommunications infrastructure; public and private communication utilities; hypermedia/multimedia object management. The middle level, services, consists of secure messaging, and enabling services. The higher level, products and structures, includes products and systems; and electronic marketplaces and electronic hierarchies. In another study [11] the authors present and use a different schema to classify electronic commerce publications, where the topics are divided into the following categories: applications; technological issues; support and implementation; and others. The applications category covers inter-organizational systems, electronic payment systems, financial services, retailing, online publishing, auctions, intra-organizational electronic commerce, education and training, marketing and advertising, and other applications. The technological issues category includes security, technological components, network technology/infrastructure, support systems, algorithm/methodology, and other technical issues. The support and implementation category embraces public policy; corporate strategy; and other support and implementation aspects. The category others includes aspects of electronic commerce that are not included in the first three categories. In a meta-analysis, Wareham et al. [20] profiled electronic commerce research publications in a period of seven years, highlighting the major domains and exploring the major themes in the area. To assign a publication to a group (i.e. major domain), the single most applicable topic-theme is assigned to it. The authors, following a similar approach to a previous study [23], determine that there are four major domains: applications and industries specific themes; information technology and infrastructure; business issues; other social issues and common cross-domain topics (e.g. research meta-studies; metrics) [20]. A recent study explored the core and emerging knowledge of electronic commerce research for the period 2006-2010, and identifies five research areas: trust, technology acceptance and technology application, electronic commerce task-related application, electronic markets, and identity and evaluation [17].

\section{Methods}

As an initial procedure we download the data of the 175 documents in the category articles published from 2007 to 2014, in the Journal of Theoretical and Applied Electronic Commerce Research, from the Scopus database. We select the documents of the type articles since it is considered the primary route to disseminate new knowledge in most of the scientific disciplines [1]. In addition, previous research suggests using the document type articles when performing bibliometric analysis [19]. This study uses two methodological approaches to achieve the objectives stated at the beginning of this research. The first approach is used for mapping international collaboration network in JTAER and the second approach allows the mapping of knowledge domains and themes in the e-commerce framework selected to the articles published in the journal.

In order to map international collaboration in this journal, first, we create a one-mode matrix (country $x$ country) with all the countries represented in each of the 175 articles published in JTAER in accordance to the defined timespan. To codify the relationship between each pair of countries in the matrix for quantitative analysis, we use the adjusted appearances. This methodology, to adjust the appearances of each country, is similar to the one used by [4], [9], [16] in their studies to adjust the appearances at the authors' level. This way, an article that represents two countries, each country receives 0.50 of a credit, in the event of three countries $1 / 3$, and so on. Once the matrix is built we graphically represent the international collaboration network by means of software [2] and then for space distribution in the graphic, we use the technique designed by [5]. We used the command Partition/Degree/All in [2] to calculate the centrality degree of each country in the collaboration network.

To identify the major domains of knowledge published in this journal we use the framework proposed by Wareham, Zheng, and Straub [20]. With the aim of mapping the knowledge domains and themes of the classification framework [20] to the articles in JTAER we use the co-word analysis technique. Co-word analysis is one of three general approaches in Information Science for showing the evolution of socio-cognitive structures from a set of documents.

To perform the co-word analysis we use a three-step methodology. First, we create a co-occurrence matrix for the main themes of the 175 articles. To codify the occurrence of the words we assign 1 for the presence and 0 for absence of the word. Second, we normalize the matrix through the Cosine Index. Third, we use the Pajek [2] software package to visualize the knowledge map. Fourth, we calculate the centrality degree of every key word in the knowledge structure. In order to subsequently analyze the results, we carry out two actions. First, we locate the key terms. Given that the centrality degree values obtained for each key word lies within a range of 0.00 to 1.00 , this range is stratified into three thresholds. In the first threshold are the key terms that pertain to the network periphery, with centrality values between 0.00 and 0.33 . Terms pertaining to the network semi-periphery are located on the second threshold, with centrality values between 0.34 and 0.66 . Finally, the third threshold includes the key terms that belong to the core of the network, and have centrality values between 0.67 and 1.00 . Second, the results of the centrality analysis based on the co-word technique are represented graphically using the Pajek software package [2]. 
With the purpose of identifying the level of international collaboration among researchers in the major domains of knowledge published by JTAER, we use the one-mode matrix (country $x$ country), with the identification of institutional and international collaboration, and link it to the matrix coded with the research themes. This integrated matrix allowed the identification of major domains and research themes where collaboration among countries occurs.

\section{International Collaboration}

Table 1 shows the patterns of collaboration in articles published in JTAER between 2007 and 2014, inclusive. $82.28 \%$ (145) are multi-authored papers. According to the depicted level of collaboration, domestic collaboration prevails (see median in Table 1). This result is similar to that reported for the network of Chinese scholars in management research [24] by using the ISI Web of Science database, but is different for the study that reported international collaboration for the discipline of management in Latin America [15].

The median of citations do not differ significantly between papers published through domestic or international collaboration. This pattern is different from that reported for the impact of Latin American research on management [15] using the ISI Web of Science database.

Table 1: Patterns of collaboration of papers published in JTAER

\begin{tabular}{|l|l|l|l|l|l|l|}
\hline \multirow{2}{*}{ Year } & \multirow{2}{*}{$\begin{array}{l}\text { Total } \\
\text { documents }\end{array}$} & \multirow{2}{*}{$\begin{array}{l}\text { Number of } \\
\text { Articles }\end{array}$} & $\begin{array}{l}\text { Single } \\
\text { Authored }\end{array}$ & Domestic & International & \multirow{2}{*}{ Times Cited } \\
\hline 2007 & 24 & 21 & 5 & 13 & 3 & 187 \\
\hline 2008 & 29 & 25 & 4 & 13 & 8 & 299 \\
\hline 2009 & 24 & 22 & 3 & 15 & 4 & 106 \\
\hline 2010 & 24 & 21 & 3 & 11 & 7 & 110 \\
\hline 2011 & 28 & 24 & 2 & 11 & 11 & 85 \\
\hline 2012 & 30 & 25 & 7 & 10 & 8 & 49 \\
\hline 2013 & 23 & 19 & 3 & 10 & 6 & 9 \\
\hline 2014 & 21 & 18 & 3 & 7 & 8 & 2 \\
\hline Total & 203 & 175 & 30 & 90 & 55 & 847 \\
\hline Median & 24 & 22 & 3 & 11 & 7,5 & 95,5 \\
\hline
\end{tabular}

Forty-four countries shape the structure of the international collaboration network through the Journal of Theoretical and Applied Electronic Commerce Research. Seven countries account for $55.4 \%$ of articles in collaboration. These countries are: USA (29), Australia (24), Spain (11), Germany (10), Switzerland (9), Netherlands (7) and Finland (7). These countries also demonstrate higher scientific research production in the area of e-commerce in the Scopus database for the timespan analyzed.

Articles published through international collaboration received 259 citations (median= 2); papers published through domestic collaboration received 474 citations (median=3) and papers that are single authored received 114 citations (median=1). The median of citations of articles on e-commerce for the timespan analyzed in the Scopus database is 2. Thus, the median of articles published through collaboration in JTAER is above the median for the research area.

Figure 1 shows the structure of the international collaboration network throughout the journal. The network density is 0.053 , and connectivity amounts to 12.48 . Countries with a higher centrality degree in the network structure are the USA, the Netherlands and Australia. These countries also have a greater presence in publications in JTAER. Italy, Germany and Spain are in a second stratum with a higher degree of centrality in the collaboration network.

The network structure as shown is not complete because thirteen countries appear isolated in the structure of the network. This means that domestic collaboration prevails in the papers published in JTAER by authors from these countries. 


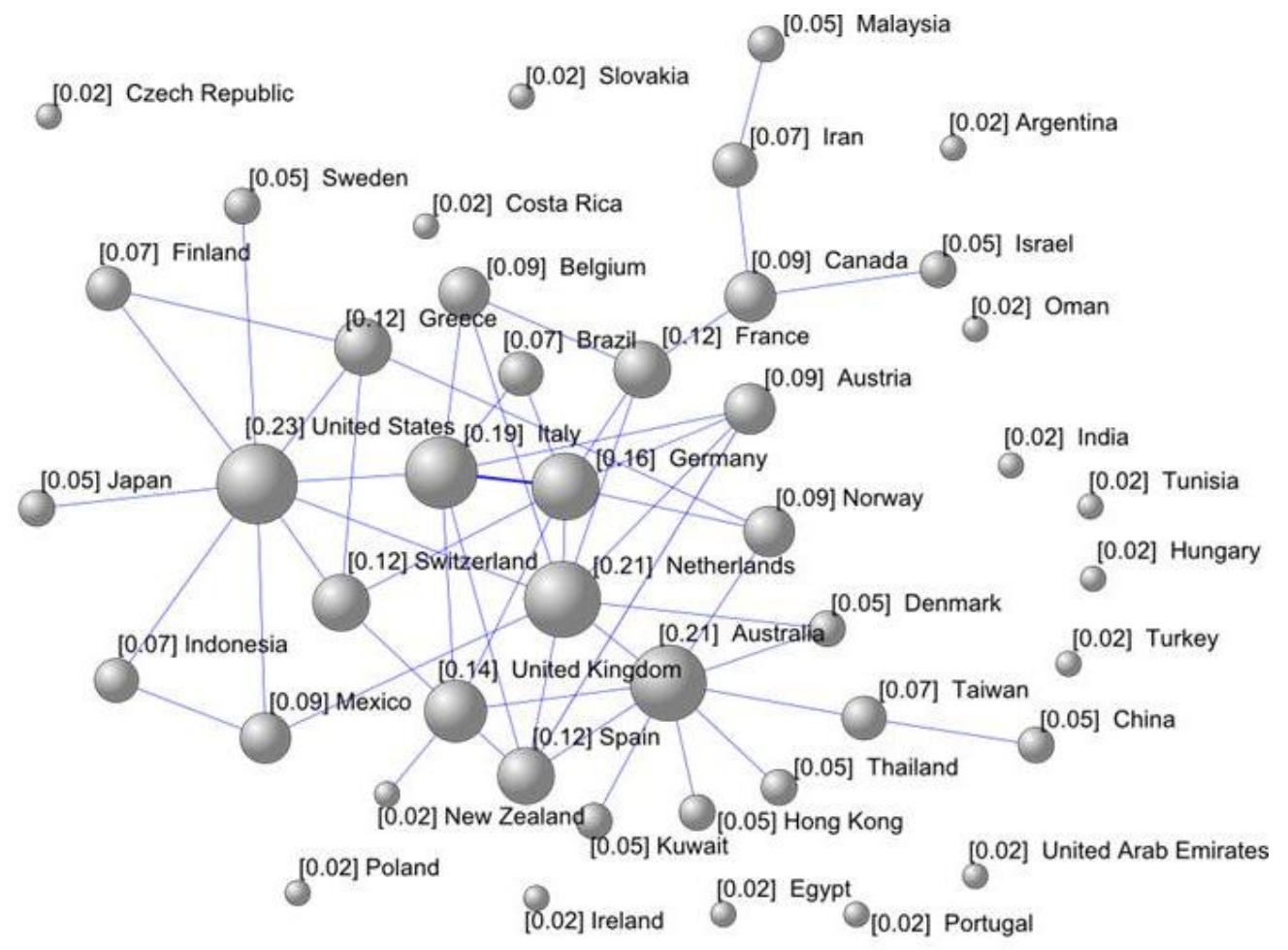

Figure1: International collaboration network through JTAER Note: Values between brackets show the centrality degree of the country

Figure 2 shows the structure of the international collaboration network by using the betweenness centrality of each country. The value of the betweenness centrality evidences which of the countries that belong to the network' structure, serves as bridge for the communication among other countries. As observed, The Netherlands, The United States and Australia are the countries that contribute the most to the growth and advancement of the network structure by incorporating new countries to the structure of the network.

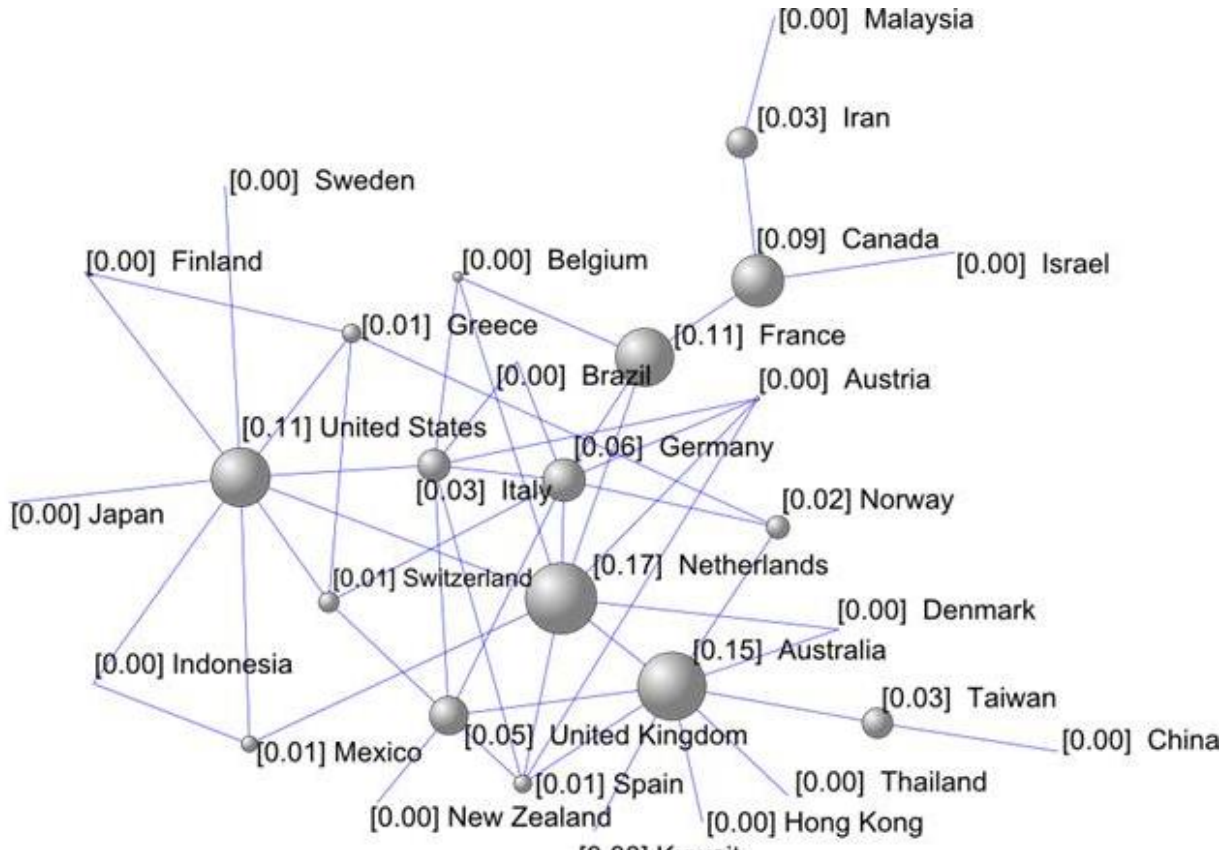

[0.00] Kuwait

Figure 2: International collaboration network through JTAER

Note: Values between brackets are the betweenness centrality of the country. Isolated countries were removed from the image 


\section{Knowledge Domains and Themes}

All articles in JTAER were mapped to the Wareham et al. [20] framework to identify central domains and themes in the Journal. Just one theme per article is allowed for each research article. Table 2 shows the top 17 research themes published in JTAER from 2007 to 2014. E-services is the most frequent research theme identified in this journal, accounting for $10 \%$ of all papers. Mobile commerce (M-Commerce) appears as the second most frequent theme. The third most frequent research theme is trust with $8 \%$. The following five most frequent research themes are data (7\%), technology (7\%), online experience (5\%), development (5\%) and supply chain (5\%).

Table 2: Frequency and percentage of major research themes through JTAER (categories adapted from [20])

\begin{tabular}{|l|l|l|}
\hline & Frequency & $\%$ \\
\hline E-services & 17 & 10 \\
\hline M-commerce & 15 & 9 \\
\hline Trust & 14 & 8 \\
\hline Data & 13 & 7 \\
\hline Technology & 13 & 7 \\
\hline Online experience & 9 & 5 \\
\hline Development & 8 & 5 \\
\hline Supply Chain & 8 & 5 \\
\hline E-government & 6 & 3 \\
\hline Integration & 6 & 3 \\
\hline Social Network & 6 & 3 \\
\hline Technology Adoption & 6 & 3 \\
\hline Auctions & 5 & 3 \\
\hline B2B & 5 & 3 \\
\hline Business Models & 5 & 3 \\
\hline Community & 5 & 3 \\
\hline Information & 5 & 3 \\
\hline
\end{tabular}

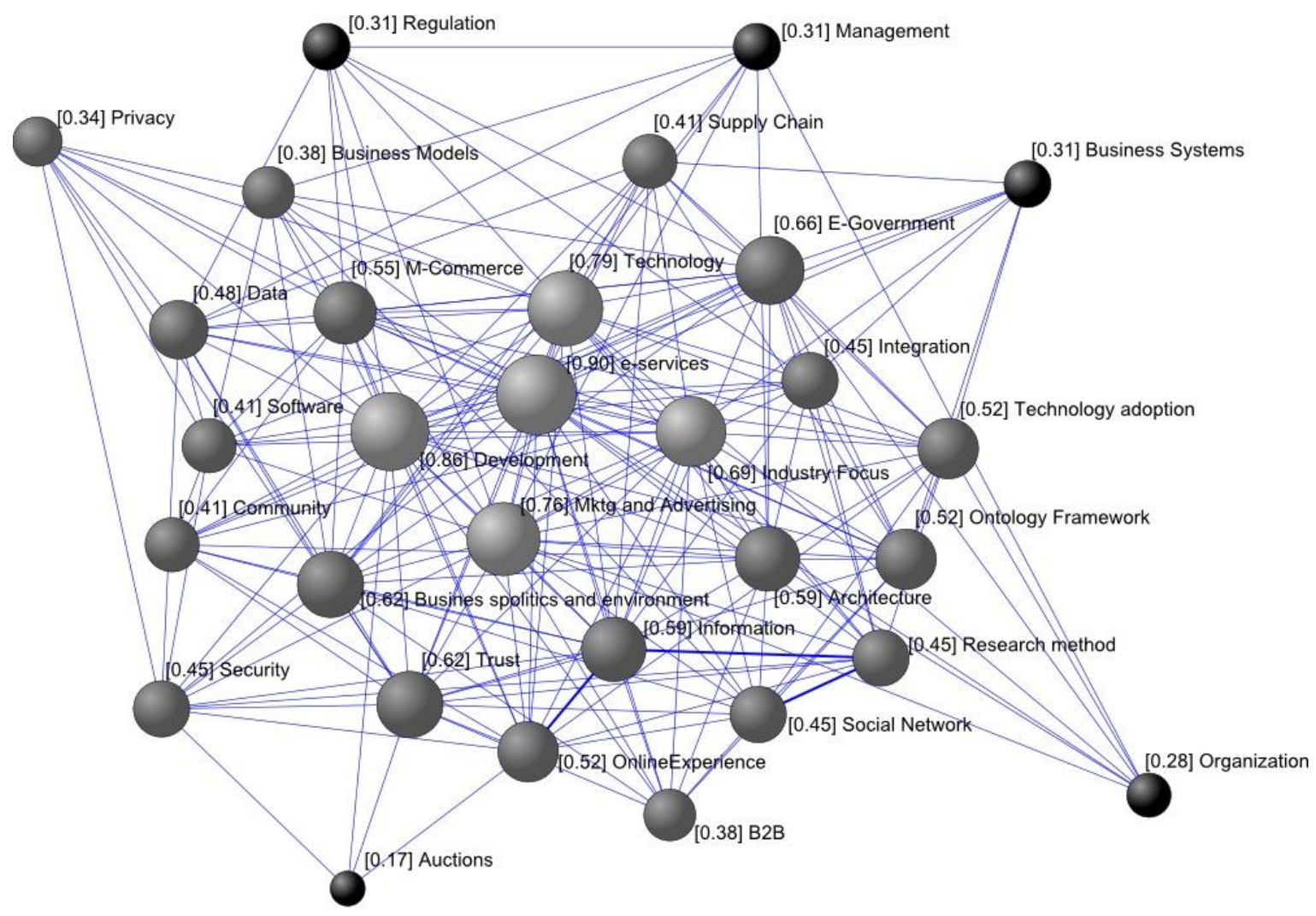

Figure 3: Research themes network through JTAER

Note: Values between brackets are the betweenness centrality of the theme

Guillermo Armando Ronda-Pupo Aurora Sánchez Narciso Cerpa 
Figure 3 shows the knowledge map of e-commerce in JTAER. The areas of e-services, technology, marketing and advertising, industry focus and development are the themes that appear in the core of the network. This means that those are central topics in this field. In the semi-periphery of the network are the themes of $m$-commerce, business models, software, e-government, ontology, information, integration, supply chain, technology adoption, research methods, trust and online experiences while the themes auctions, organization, regulations, management and business systems appear as peripheral themes.

Table 3 shows the results of classifying all research articles published in JTAER on the major domains of the framework [20]. The finding suggests that the largest number of articles investigated fits primarily in the domain other social issues with $28.5 \%$ of the total articles published in this journal. The second most relevant domain is applications and industry specific themes with $26.8 \%$ of the articles. The third most researched domain of analysis is information technology and infrastructure with $21.1 \%$ of the articles.

Table 3: Frequency of articles by knowledge domains and year

\begin{tabular}{|l|l|l|l|l|l|l|}
\hline Year & $\begin{array}{l}\text { Information } \\
\text { Technology } \\
\text { and } \\
\text { Infraestructure }\end{array}$ & $\begin{array}{l}\text { Applications } \\
\text { and Industry } \\
\text { Specific } \\
\text { Themes }\end{array}$ & $\begin{array}{l}\text { Business } \\
\text { Issues }\end{array}$ & $\begin{array}{l}\text { Other } \\
\text { Social } \\
\text { Issues }\end{array}$ & $\begin{array}{l}\text { Other themes } \\
\text { not included } \\
\text { in the } \\
\text { framework }\end{array}$ & Total \\
\hline 2007 & 5 & 8 & 3 & 4 & 1 & 21 \\
\hline 2008 & 8 & 12 & 2 & 2 & 1 & 25 \\
\hline 2009 & 7 & 9 & 4 & 2 & 0 & 22 \\
\hline 2010 & 3 & 3 & 2 & 11 & 2 & 21 \\
\hline 2011 & 6 & 4 & 3 & 9 & 2 & 24 \\
\hline 2012 & 2 & 9 & 0 & 12 & 2 & 25 \\
\hline 2013 & 6 & 1 & 4 & 7 & 1 & 19 \\
\hline 2014 & 0 & 1 & 2 & 3 & 12 & 175 \\
\hline Total & 37 & 47 & 20 & 50 & 21 & \\
\hline
\end{tabular}

\section{Knowledge Domains and International Collaboration}

In terms of international collaboration patterns by research theme, Table 4 shows the countries that display the highest numbers of contributors in international collaboration and major research themes. The results positioned the United States and Australia as the first and second countries that show the highest rates of international collaboration. Among the countries showing international collaboration, e-services is the most important theme, with $16.4 \%$ of all research articles in international collaboration. The second most important theme in international collaboration is mobile commerce with $12.7 \%$ of all articles. In third place are supply chain and trust, each accounting for $10.9 \%$ of all research themes in international collaboration.

Table 4: Frequency of articles in International collaboration by country and research theme

\begin{tabular}{|c|c|c|c|c|c|c|}
\hline Research Theme & $\begin{array}{l}\text { United } \\
\text { States }\end{array}$ & Australia & Germany & Finland & Netherlands & Total \\
\hline E-services & 3 & 5 & 1 & & & 9 \\
\hline M-commerce & 3 & 3 & & 1 & & 7 \\
\hline Supply Chain & 3 & 2 & & & 1 & 6 \\
\hline Trust & 1 & 1 & 3 & 1 & & 6 \\
\hline Data & 1 & & & 2 & 2 & 5 \\
\hline Online Experience & 2 & 1 & 1 & 1 & & 5 \\
\hline Technology & 3 & 1 & & 1 & & 5 \\
\hline Technology adoption & 2 & 2 & & & 1 & 5 \\
\hline Community & 1 & & 2 & & 1 & 4 \\
\hline Auctions & 1 & 2 & & & & 3 \\
\hline
\end{tabular}

The level of international collaboration among researchers, from the nine most frequent contributing countries publishing in JTAER, is, first, the other social issues knowledge domain (40\% of all international collaboration), with researchers from France, Brazil, Australia, the United States, Germany and Spain collaborating. The second highest ranked knowledge domain is applications and industry specific themes (20\% of all international collaboration) with Australia and the United States as the major collaborators in this domain. The third highest ranked domain is other themes not included in the framework which includes themes that do not fit in the selected framework (17\% of all international collaboration) as seen in figures 4 and 5 .

Guillermo Armando Ronda-Pupo Aurora Sánchez Narciso Cerpa 


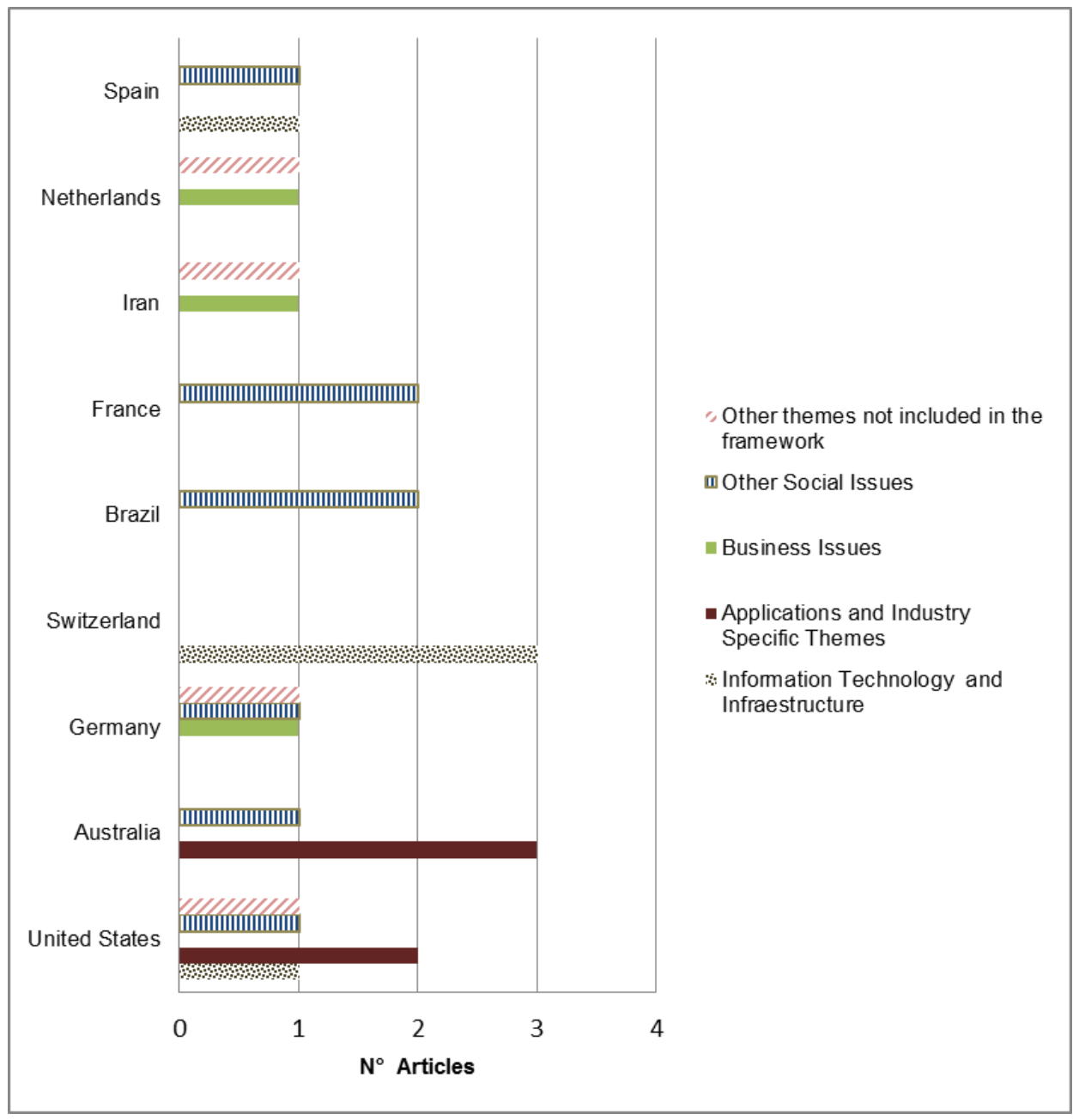

Figure 4: International collaboration by country and knowledge domain through JTAER

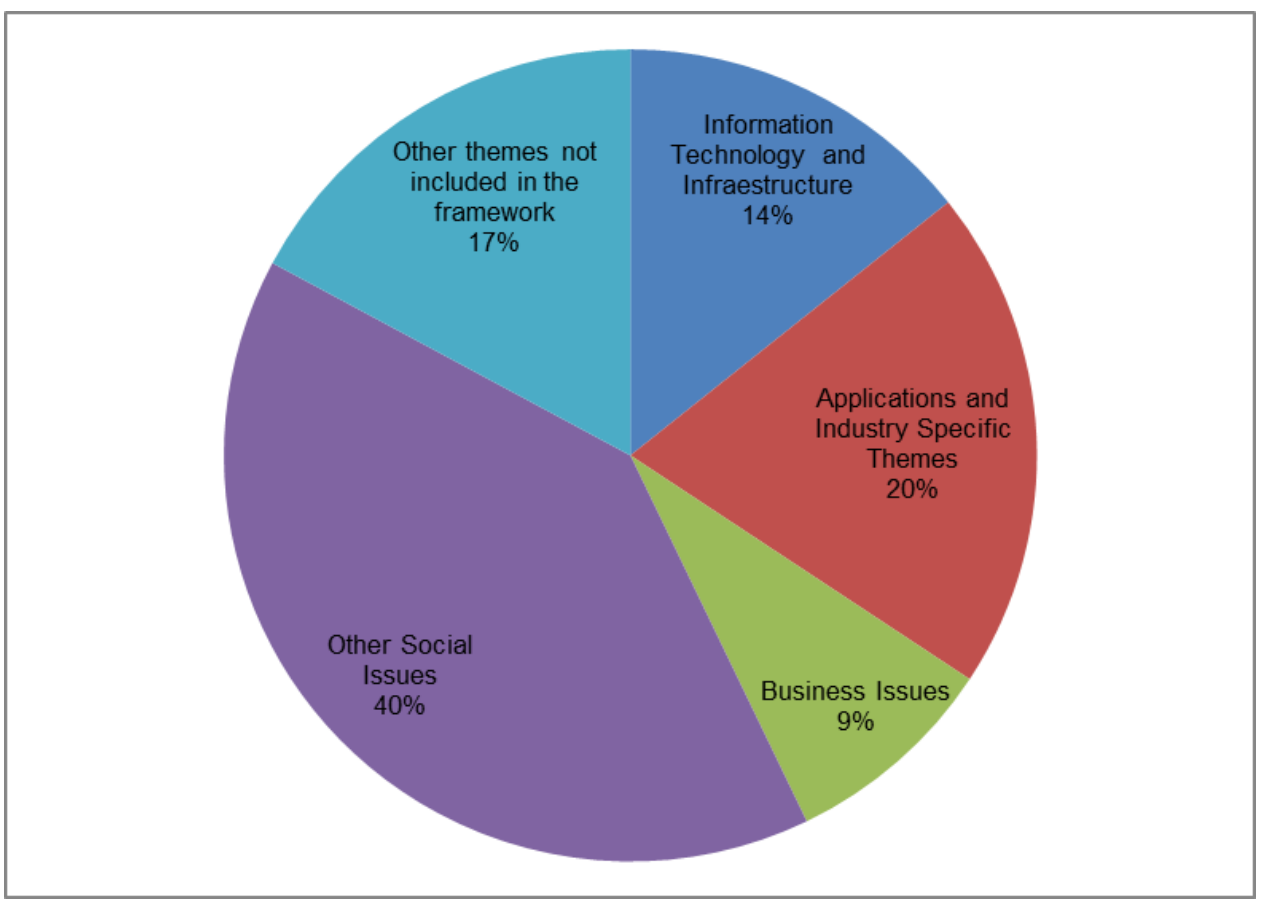

Figure 5: International collaboration by knowledge domain in JTAER

Editorial: Mapping the Structure of International Research Collaboration Network and Knowledge Domains on Electronic Commerce in the Journal of Theoretical and Applied Electronic Commerce Research
Guillermo Armando Ronda-Pupo Aurora Sánchez Narciso Cerpa 


\section{Discussion and Conclusions}

The Journal of Theoretical and Applied Electronic Commerce Research is an international journal that shows consolidation and stability according to its Impact Factor and SJR, and it is regarded as the leading journal on electronic commerce in Latin America. The main purposes of this study were to: (a) discover and illustrate the scientific knowledge structure of e-commerce present in JTAER, and the level of collaboration among researchers publishing there; (b) identify the major domains of knowledge published in the journal; and (c) to depict the knowledge domains and themes where international collaboration is already taking place. This investigation reveals that:

- The United States and Australia are the countries that have contributed the most to the growth and consolidation of the international collaboration network research on Electronic Commerce through JTAER in the period 2007-2014.

- Major countries publishing in JTAER are Australia, the United States and North European countries. Regions such as Latin America and Caribbean countries have a low presence in the articles published in the journal. Collaboration among researchers in this journal is high, $82.28 \%$, of all articles published since 2007. This collaboration occurs mainly at the domestic level.

- When mapping articles published in JTAER toward the e-commerce framework proposed by Wareham, Zheng, and Straub [20] the major unique themes are e- services, mobile commerce, and trust. However, the themes at the core of the network are e-services, technology, marketing and advertising, industry focus and development, demonstrating that these are central themes in this field.

- Considering only the articles in international collaboration, we can see that e-services and mobile commerce are the primary themes, with $29 \%$ of the total articles in international collaboration. Major domains of research in JTAER as a whole are other social issues and applications and industry specific themes.

These results show that although only seven countries account for more than fifty percent of the international collaboration network on electronic commerce at JTAER, the collaboration is considerably high. The study also shows the most important themes and knowledge domains of the articles published in the journal. These results suggest that to develop more collaboration with countries at the core of the network, a possible strategy would be to incorporate editorial board members from those countries that are not currently in the research network of JTAER and to promote the journal in those research communities to incorporate new countries to the network structure. Future research should compare these results with those from other electronic commerce journals.

\section{References}

[1] J. Adams and K. Gurney. (2013, May) Leading research economies in a changing knowledge network. Spain. Global Research Digests. [Online]. Available: http://sciencewatch.com/sites/sw/files/sw-article/media/grrspain mn.pdf

[2] V. Batagelj and A. Mrvar. Pajek, Analysis and visualization for large networks, in Graph Drawing Software: Mathematics and Visualization (M. Junger and P. Mutzel, Eds.). Berlin: Springer-Verlag, 2004, pp. 77-103.

[3] U. Finardi, Scientific collaboration between BRICS countries, Scientometrics, vol. 102, no. 2, pp.1139-1166, 2015.

[4] J. Heck and P. Cooley, Most frequent contributors to the finance literature, Financial Management, vol. 17, no. 3, pp. 100-108, 1988.

[5] T. Kamada and S. Kawai, An algorithm for drawing general undirected graphs, Processing Letters, vol. 31, no 1 , pp. 7-15,1989.

[6] J. S. Katz and B. R. Martin, What is research collaboration?, Research Policy, vol. 26, no. 1, pp. 1-18, 1997.

[7] S. Lee, J. Choi and H. Kim, Semantic network analysis on the MIS research keywords: APJIS and MIS quarterly 2005 2009, Asia Pacific Journal of Information Systems, vol. 20, no. 4, pp. 25-51, 2010.

[8] J. M. Levitt and M. Thelwall, Citation levels and collaboration within library and information science, Journal of the American Information Science and Technology, vol. 60, no. 3, pp. 434-442, 2009.

[9] A. J. Morrison and A. C. Inkpen, An analysis of significant contributions to the international business literature, Journal of International Business Studies, vol. 22 no. 1, pp. 143-153, 1991.

[10] F. Narin and E. S. Witlow, Measurement of scientific cooperation and coauthorship in CEC-related areas of science, Commission of the European Communities, Technical Report EUR 12900 EN/1, Brussels, Luxembourg, 1990.

[11] E. W. Ngai and F. K. T. Wat, A literature review and classification of electronic commerce research, Information \& Management, vol. 39, no. 5, pp. 415-429, 2002.

[12] H. M. Puuska, R. Muhonen and Y. Leino. International and domestic co-publishing and their citation impact in different disciplines, Scientometrics, vol. 98, no. 2, pp. 823-839, 2014. 
[13] M. Qiang, S. Muthukrishnan, B.Thompson, and G. Cormode. Modeling collaboration in academia: A game theoretic approach, in Proceedings of the Companion Publication of the 23rd International Conference on World Wide Web Companion, Seoul, 2014, pp. 1177-1182.

[14] J. Quu, International collaboration in science: A Chinese perspective, National Science Review, vol. 1, no. 2, pp. 318-321, 2014

[15] G. A. Ronda-Pupo, C. Diaz-Contreras, G. Ronda-Velázquez, and J. C. Ronda-Pupo, The role of academic collaboration in the impact of Latin-American research on management, Scientometrics, vol. 102, no. 2, pp. 1435-1454, 2015.

[16] S. A. Shane, Who is publishing the entrepreneurship research?, Journal of Management, vol. 23, no. 1, pp. 8395, 1997.

[17] W. Shiau and Y. K. Dwivedi, Citation and co-citation analysis to identify core and emerging knowledge in electronic commerce research, Scientometrics, vol. 94, no. 3, pp.1317-1337, 2013.

[18] A. F. J. Van Raan, The influence of international collaboration on the impact of research results - some simple mathematical considerations concerning the role of self-citations, Scientometrics, vol. 42, no. 3, pp. 423-428, 1998.

[19] A. F. J. Van Raan, Advances in Bibliometric Analysis: Research Performance Assessment and Science Mapping. Dordretch: Portland Press, 2014.

[20] J. Wareham, J.G. Zheng and D. Straub, Critical themes in electronic commerce research: A meta-analysis, Journal of Information Technology, vol. 20, no. 1, pp. 1-19, 2005.

[21] Q. Yu, H. Shao, C. Long, and Z. Duan, The relationship between research performance and international research collaboration in the C\&C field, Experimental \& Clinical Cardiology, vol. 20, no. 6, pp. 145-153, 2014.

[22] G. Zacca-Gonzalez, Z. Chinchilla-Rodriguez, B. Vargas-Quesada, and F. D. Moya-Anegon, Bibliometric analysis of regional Latin America's scientific output in public health through SCImago journal \& country rank, BMC Public Health, vol. 14, no.1, pp. 632, 2014

[23] L. Zhai, X. Li, X. Yan, and W. Fan, Evolutionary analysis of collaboration networks in the field of information systems, Scientometrics, vol. 101, no. 3, pp. 1657-1677, 2014.

[24] L. Zhai, X. Yan, J. Shibchurn, and X. Song, Evolutionary analysis of international collaboration network of Chinese scholars in management research, Scientometrics, vol. 98, no. 2, pp. 1435-1454, 2014.

[25] V. Zwass, Electronic commerce: Structures and issues, International Journal of Electronic Commerce, vol. 1, no. 1 , pp. 3-23,1996. 